\title{
Tracking fluvial sediment sources through the lanthanide traces. Experimental method applied on the Jiu river basin (Romania)
}

MoroșAnU GABriElA ADINA ${ }^{1,2,3}$, TRAISTĂ EUGEN ${ }^{4}$, ZAHARIA LILIANA ${ }^{1}$, BELLEUDY PHILIPPE ${ }^{2}$

${ }^{11}$ Faculty of Geography, Bucharest Univ., Bd. N.Bălcescu 1, 010041, Romania (*gabriela.adina.m@gmail.com) ${ }^{2}$ UGA-IGE, CS 4070038058 Grenoble Cedex 9, France

${ }^{3}$ Institute of Geography of the Romanian Academy, Romania ${ }^{4}$ Faculty of Mining, Petroșani Univ., Romania

The detection of fine sediment formation sources delivered in a river basin is a topical concern in the context of the management of hydrological resources and pollutants that affect the water-sediment interface, but it can also turn into a Pandora's box challenge.

The main purpose of the study was to try and test appropriate methods for connecting recent alluvial deposits in the lower sector of the Jiu River (SW Romania) with their sources. The Jiu river basin is an important supplier of fine sediments of the Danube and, due to its geological complexity (its substrate is formed on both crystalline, limestone and detrital rocks), requires special attention when studying the geochemical footprint that certain rocks can leave on fine sediments, a fact which, in a hydrological context, would be easily omitted at the regional scale of the territory occupied by the Jiu basin $\left(\sim 10,000 \mathrm{~km}^{2}\right)$.

The sediment samples came both from upstream keypoints in the riverbeds and on the slopes (19 of them), while the remaining 11 were sampled on an alluvial depozit forming the Jiu riverbank in its downstream sector. The samples were decomposed into lanthanum elements using Rigaku Supermini X-ray Fluorescence Spectrography. The initial proportions of each of the 14 lanthanides were normalized with the known proportion of chondrites.

The statistical method using the proportions of lanthanides consisted in grouping the samples from the upstream sources according to the common geological characteristics into 6 categories (according to their geochemical properties related to lanthanides). The interpretation of the 14 lanthanide distribution was done in two stages: a) in the first step the potential upstream alluvial sources were attributed from a general perspective (at the level of the 6 source zones), and b) in the second step corresponding to a finer spatial scale, we compared the results for the 11 downstream alluvial layers with the characteristics of the samples from the potential source areas. 